\title{
ANALISIS DAN PERANCANGAN ECOMMERCE PADA BATIK TULIS TENGAH SAWAH NGADIROJO
}

\author{
Tri Hariyati' ${ }^{1}$ Bambang Eka Purnama², Sukadi $^{3}$ \\ ${ }^{1}$ Universitas Surakarta, ${ }^{2}$ STMIK Nusa Mandiri Jakarta, ${ }^{3}$ STKIP PGRI Pacitan \\ 1yutrihariyati@ymail.com, ${ }^{2}$ bambang@nusamandiri.ac.id, ${ }^{3}$ kadibarvan@yahoo.com
}

\begin{abstract}
Electronic Commerce is defined as the process of buying and selling of products, services and information that will be conducted electronically by using computer network. E-Commerce can involve electronic funds transfer, electronic data interchange, automated inventory management systems, and automated data collection systems. Batik tulis Tengah Sawah Ngadirojo to date in the marketing and sales process is still conventional. The purpose of this study was to analyze the sales system is running and doing the design of e-commerce in the Batik Tulis Tengah Sawah located in Ngadirjo. The method used is to provide an overview of e-commerce to the Batik Tulis Tengah Sawah Ngadirojo. Based on these issues, then made the design of e-commerce in the Batik Tulis Tengah Sawah Ngadirojo and is expected to help consumers to find out the availability of existing products without having to visit a workshop. With the design of ecommerce is that consumers can make purchases online and payment products made through bank transfer. Addition was made to expand the marketing and sales of products, e-commerce is expected to improve the quality of service to consumers.
\end{abstract}

\section{Keywords: E-commerce; Batik Tulis; Batik Tulis Tengah Sawah}

\subsection{Latar Belakang Masalah}

Batik Tulis Tengah Sawah adalah batik tulis yang terdiri dari berbagai macam pengobatan secara stantis, alami dan jawi, hingga saat ini proses penjualannya masih bersifat konvensional dimana pembeli berhubungan langsung dengan datang ke toko tersebut. Dengan demikian pembeli membutuhkan biaya yang lebih besar dan waktu yang cukup lama untuk membeli produk batik yang diinginkan, selain itu pembeli kurang mendapatkan informasi tentang motif batik yang ada ditempat batik tersebut. Pada saat ini era globalisasi, perkembangan teknologi telekomunikasi dan komputer sudah berkembang pesat. Internet merupakan media informasi yang dapat di akses secara lintas negara karena sifat internet tidak mengenal batasan geografis.

\subsection{Rumusan Masalah}

a. Saat ini kondisi pemasaran masih bersifat konvensional.

b. Bagaimana merancang ecommerce pada Batik Tulis Tengah Sawah Ngadirojo?

\subsection{Batasan Masalah}

1. Penyajian perancangan informasi penjualan meliputi informasi jenis produk dengan fasilitas katalog, informasi pemesanan, konfirmasi pembayaran dan cek produk.

2. Produk yang digunakan sebagai objek penjualan adalah produk-produk Batik Tulis Tengah Sawah meliputi kemeja batik tulis, kemeja batik sutra untuk pria, kain

kemeja, kain sarung, kain selendang.

\subsection{Tujuan Penelitian}

Menghasilkan rancangan ecommerce sebagai sarana promosi maupun penjualan pada Batik Tulis Tengah Sawah.

\subsection{Manfaat Penelitian}

a.Memberi gambaran tentang e_commerce kepada pihak Batik Tulis Tengah Sawah

b. Menjadi evaluasi atau tinjauan ulang bagi pihak lain yang mengambil materi penelitian yang sama dengan laporan ini.

\section{Landasan Teori}

\subsection{Pengertian Analisis}

Analisis dilakukan untuk memperoleh kesimpulan dengan jelas dan lebih spesifik sehingga membantu dalam perancangan sistem yang lebih baik. Analisis juga dilakukan untuk mengetahui sistem informasi yang akan dibuat dapat membantu dalam pengembangan perusahaan. ( Teguh Wahyono, 2004 $: 12$ ).

\subsection{Pengertian Perancangan}

Menurut Dr. Azhar Susanto, Mbus, (2004:51). Perancangan adalah kemampuan untuk membuat beberapa alternatif pemecahan masalah.

\subsection{Pengertian PHP}

Pengembangan Web yang disisipkan PHP singkatan dari PHP Hypertext Preprocessor yang digunakan sebagai bahasa script server-side dalam pada dokumen HTML. (Kasiman Peranginangin, 2006:2) 
Penggunaan PHP memungkinkan Web dapat dibuat dinamis sehingga maintenance situs Web tersebut menjadi lebih mudah dan efisien.

PHP merupakan softwere Open-Source yang disebarkan dan dilisensikan secara gratis serta dapat di-download secara bebas dari situs resminya http://www.php.net

\subsection{Definisi E-commerce}

Electronic commerce (e-commerce) atau perdagangan lewat elektronik adalah perdagangan yang dilakukan dengan memanfaatkan jaringan telekomunikasi terutama internet. Internet memungkinkan orang atau organisasi yang berada pada jarak yang jauh dapat saling berkomunikasi dengan biaya yang murah. Hal ini kemudian dimanfaatkan untuk melakukan transaksi perdagangan.(Rahmat HM,2010:14).

Electronic commerce, juga disebut sebagai ecommerece, merupakan sebuah transaksi pembelian dan penjualan baik produk barang

atau jasa melalui sitem elektronik seperti internet dan jaringan komputer lainnya.(ANDI,2009:1)

\subsection{Kajian Pustaka}

Pada tahun 2011, G Bangkit Sukma Nugraha menyusun skripsi yang berjudul Analisis dan Pembuatan Ecommerce pada Perusahaan Sandal Batik Sagitria Collection. Dijelaskan bahwa, Toko Sandal Batik Sagitria Collection selama ini melakukan transaksi penjualan hanya secara offline, begitu juga dengan media promosi yang digunakan.

Dengan adanya e-commerce pada Toko Sandal Batik Sagitria Collection diharapkan dapat menjadi media promosi yang tepat dan meningkatkan penjualan serta memperluas pemasaran. Berdasar pada masalah tersebut, maka dibuat e-commerce untuk kerajinan sandal batik pada"Sagitri Collection". E-commerce yang akan dibuat pada Toko Sandal Batik Sagitria Collection dapat membantu konsumen untuk mengetahui ketersediaan produk yang ada tanpa harus mengunjungi workshop. Dengan adanya ecommerce ini maka konsumen dapat melakukan transaksi pembelian produk onnline dan pembayarannya dilakukan melalui transfer antar bank. Selain dibuat untuk memperluas

pemasaran dan penjualan produk, e-commerce ini diharapkan dapat meningkatkan kualitas pelayanan terhadap para konsumen.

\section{Berkas Konvensional}

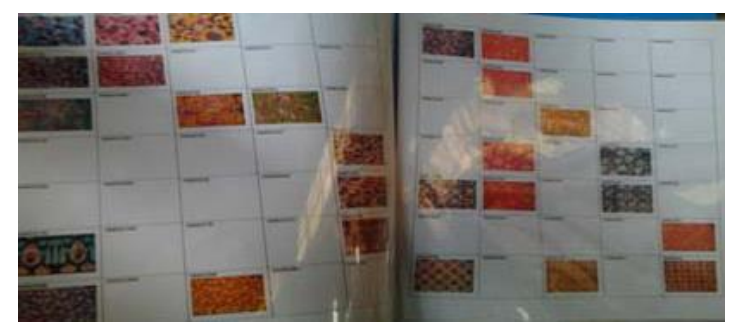

Gambar 2.1 Berkas Konvensional

\subsection{Perancangan Sistem}

\section{a. Diagram Konteks}

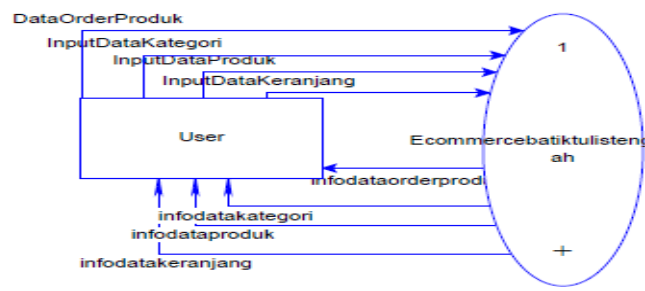

Gambar 3.1 Diagram Konteks

\section{b. Dfd Level 1}

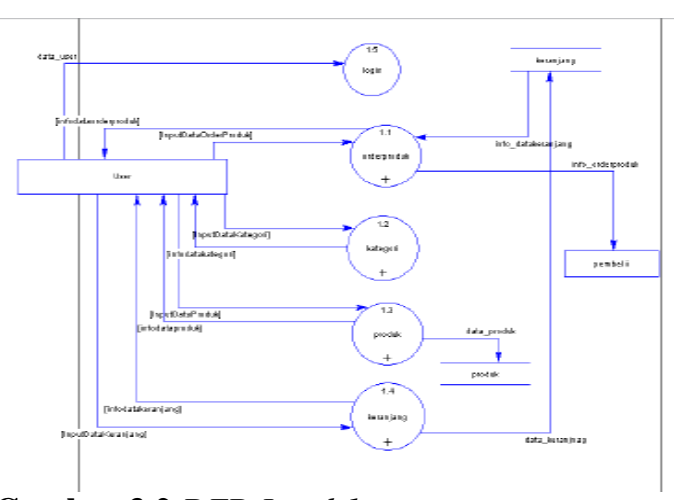

Gambar 3.2 DFD Level 1

\section{b. Dfd Level 1 Order produk}

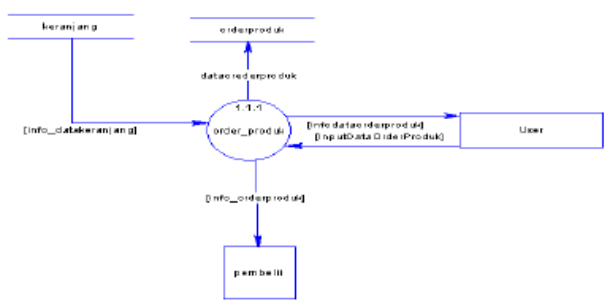

Gambar 3.3 Dfd level 1 Order produk

\section{c. Dfd Level 1 kategori}

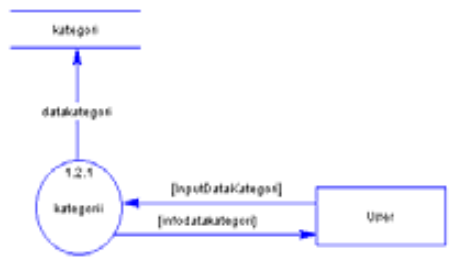

Gambar 3.4 Dfd level 1 kategori 
d. Dfd Level 1 Data produk

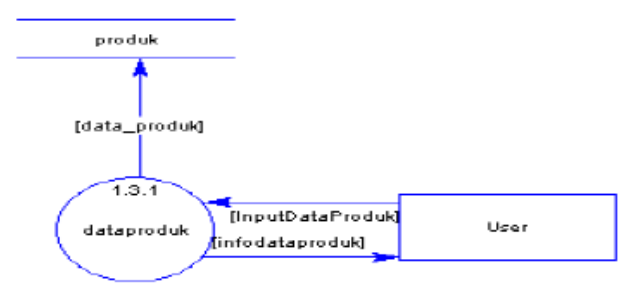

Gambar 3.5 Dfd level 1 data produk

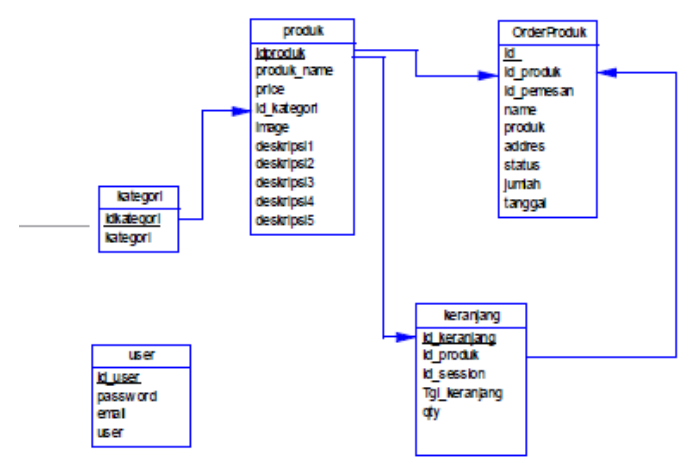

Gambar 3.7 Relasi tabel

\subsection{IMPLEMENTASI SISTEM}

Halaman Home

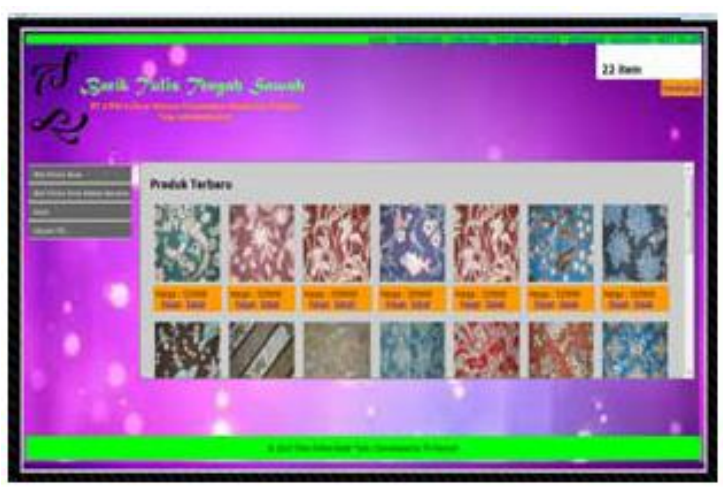

Gambar 4.1. Halaman Home

Halaman detail batik

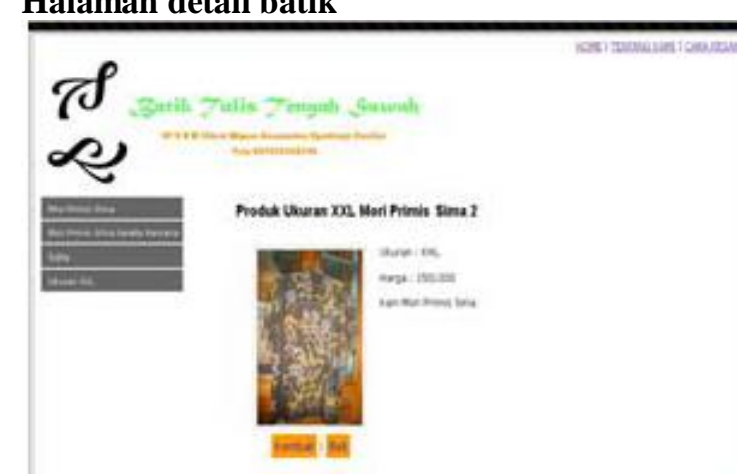

\section{Gambar 4.2. Halaman Detail batik}

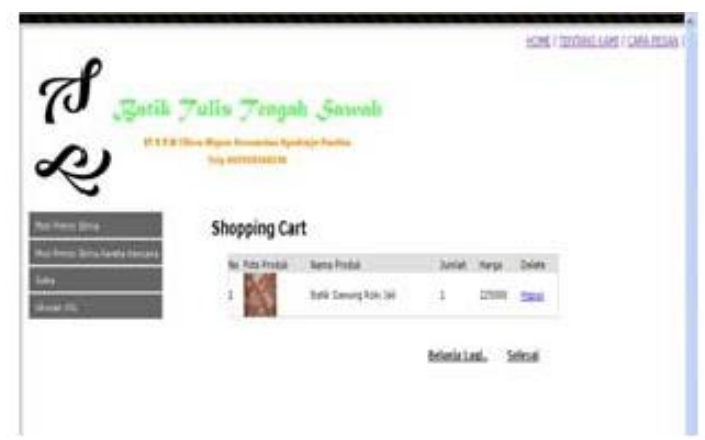

Gambar 4.3. Halaman pemesanan

Form pemesanan

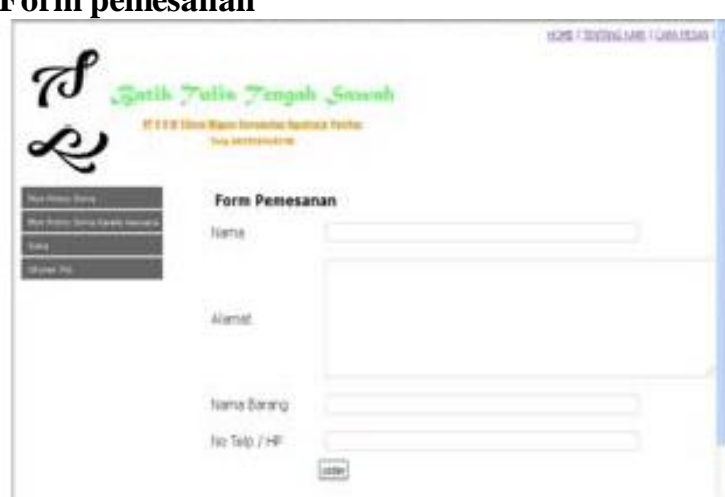

Gambar 4.4. From pemesanan

Halaman keranjang

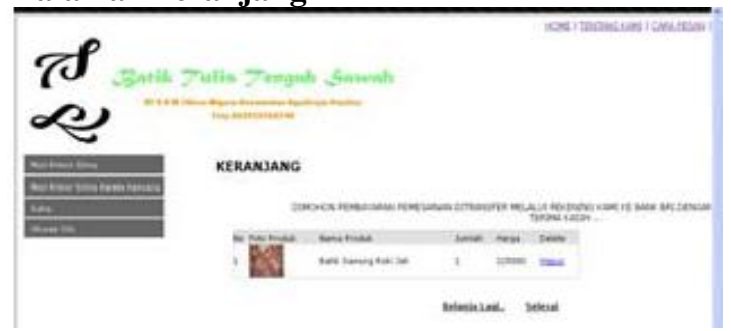

Gambar 4.5. Halaman keranjang

Halaman cek tarif pengiriman

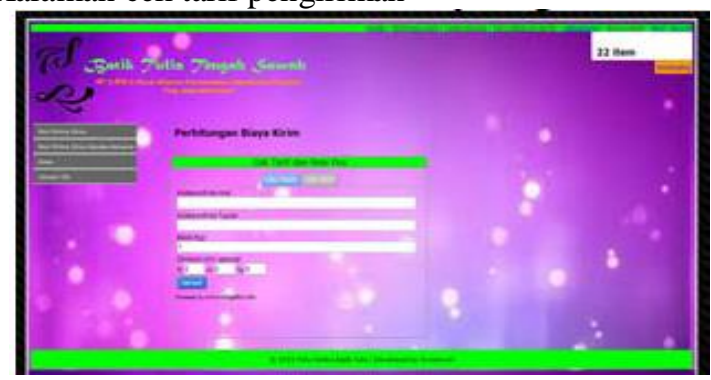

Gambar 4.6. Halaman cek tarif peniriman 


\section{Halaman cek resi}

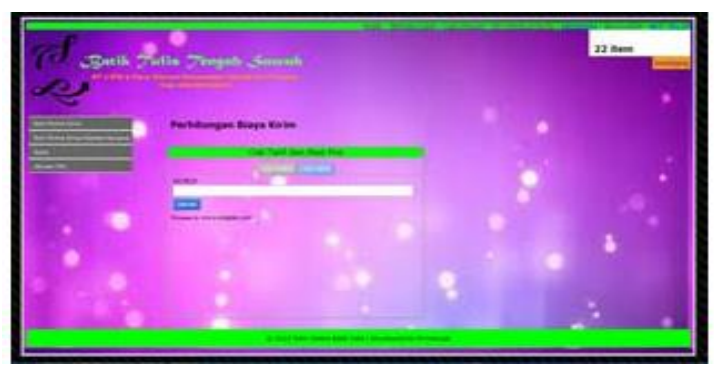

Gambar 4.7. Halaman cek resi

\section{Halaman tentang kami}

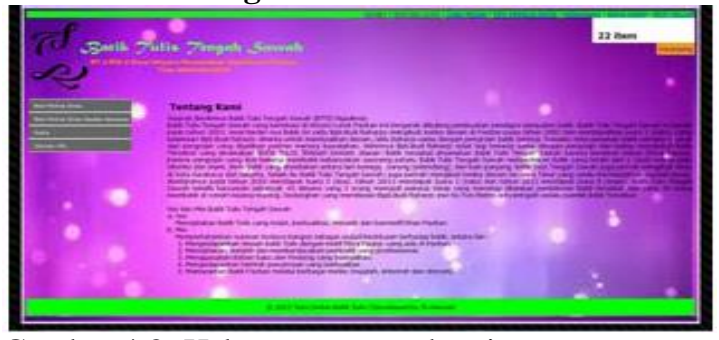

Gambar 4.8. Halaman tentang kami

Halaman cara pemesanan

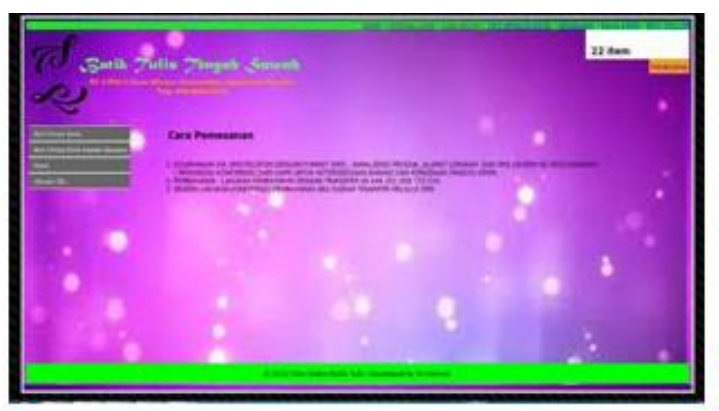

Gambar 4.9. Halaman cara pemesanan Halaman tips memilih batik

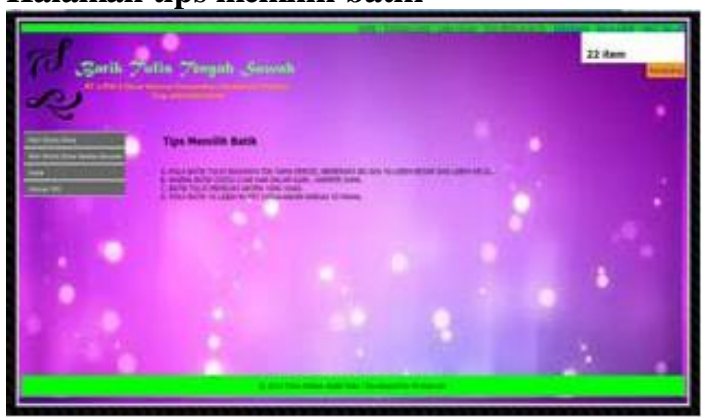

Gambar 4.10. Halaman tips memilih batik

Halaman best seller

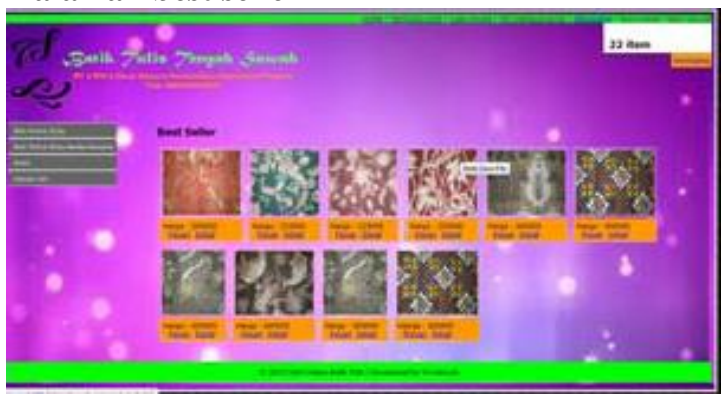

Gambar 4.11. Halaman best seller

\section{Halaman login admin}

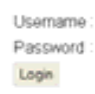

Gambar 4.12. Halaman login admin

\section{Halaman home admin}

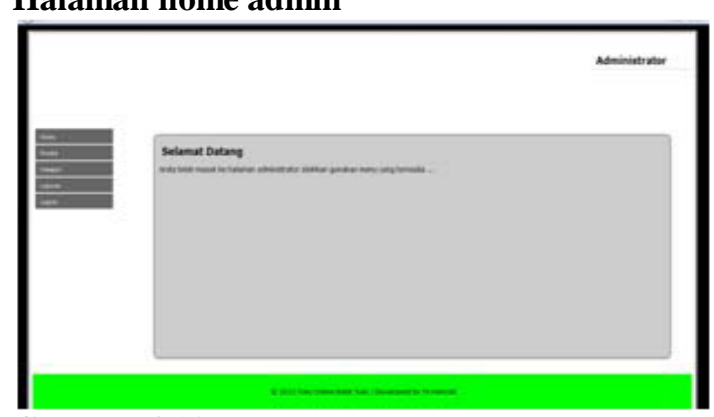

Gambar 4.13. Halaman home admin

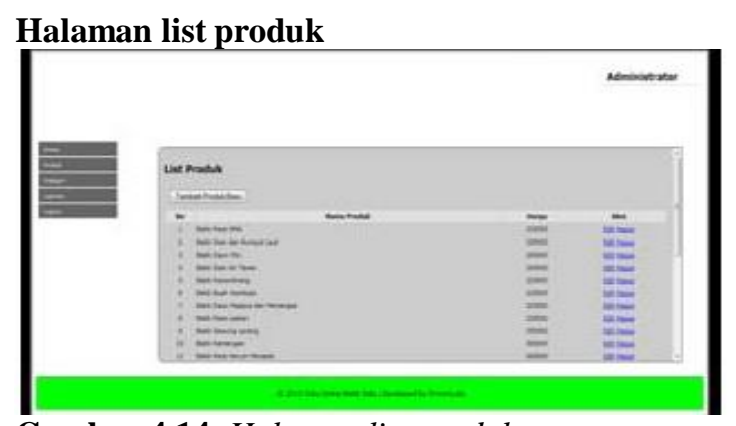

Gambar 4.14. Halaman list produk

\section{Halaman list kategori}

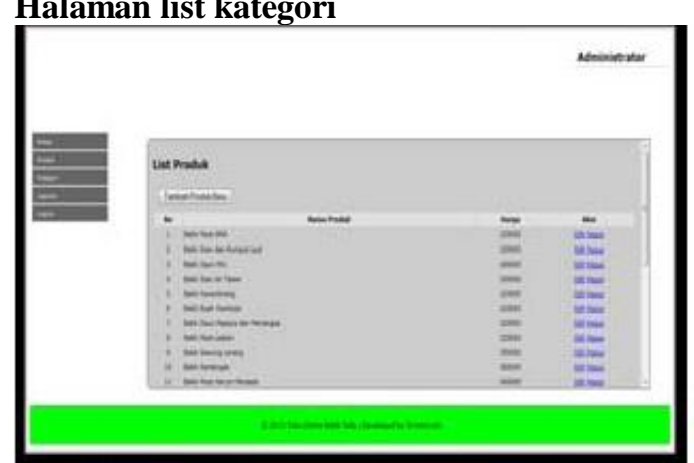

Gambar 4.15. Halaman list kategori 


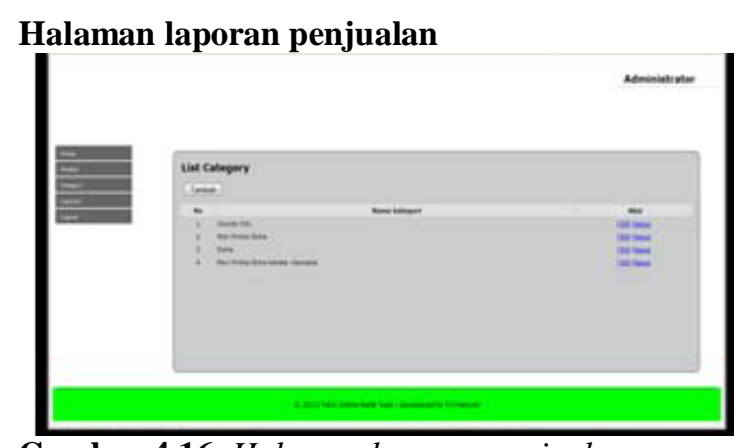

Gambar 4.16. Halaman laporan penjualan

\section{Halaman logout admin}

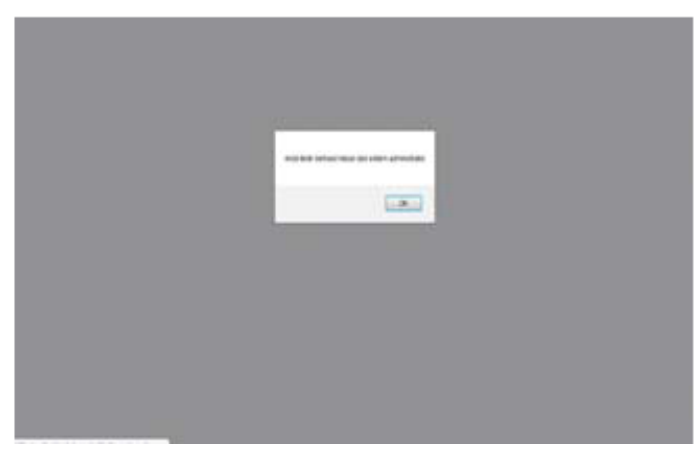

Gambar 4.17. Halaman logout admin

\subsection{Kesimpulan}

1. Saat ini sistem promosi pada Batik Tulis Tengah Sawah masih bersifat konvensional, dalam mempromosikan barang masih menggunakan katalog dan dalam menyimpan data pelanggan serta penjualan perbulan juga masih dicatat dengan menggunakan buku.

2. Dari sistem promosi yang ada pada Batik Tulis Tengah Sawah Ngadirojo tersebut maka peneliti tertarik untuk membuat Analisis dan Perancangan E_commerce Pada Batik Tulis Tengah Sawah Ngadirojo tersebut.

\subsection{Saran}

Perancangan ecommerce ini harus diperhatikan, untuk penambahan perancangan fitur pelanggan dan desain tampilan yang lebih menarik lagi agar bisa lebih menarik perhatian.

\section{DAFTAR PUSTAKA}

ANDI, Toko Onnline dengan ZenCart, Yogyakarta, 2009

Rahmat HM, Tuntunan PROMOSI GRATIS di Internet, Banguntapan Jojakarta, 2010

Teguh Wahyono.Sistem Informasi : Konsep Dasar, Analisis Desain dan Iplementasi. Yogyakarta : Penerbit Graha Ilmu.2001 


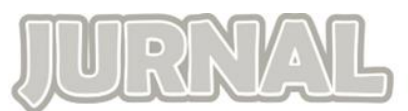

